\title{
Determinants of Internal Whistleblowing Intentions in Public Sector: Evidence from Indonesia
}

\author{
Ari Kuncara W..$^{1 *}$, Rizka Furqorina $^{2}$, Payamta ${ }^{3}$ \\ ${ }^{1}$ Universitas Sebelas Maret, Indonesia \\ ${ }^{2}$ Universitas Sebelas Maret, Indonesia \\ ${ }^{3}$ Universitas Sebelas Maret, Indonesia
}

\begin{abstract}
This research aims to examine the influence of ewuh-pakewuh culture, attitude, perceived behavioral control, personal responsibility for reporting, and personal cost of reporting on the whistleblowing intentions among civil servants in the Directorate General of Taxation and perceived organizational support as moderation variable. This research uses primary data collected through the questionnaire. The data analysis is Structural Equation Model (SEM) with SmartPLS 2.0 software. This study employs a whole population as sample resulting 117 employees of Directorate General of Taxation. This research is divided into two scenarios: less serious corruption case and serious corruption case. The results of this research indicate mixed results. It seems that level of violation might affect the result.
\end{abstract}

\section{Introduction}

Indonesian government introduces whistleblowing as a mean to combact corruption. Cases of corruption occurred in Indonesia has became a common phenomenon. Corruption from year to year is increasing, both in terms of quantity and nominal financial losses. Various efforts have been implemented by the government to prevent and combat corruption in Indonesia. Among the efforts, the government has issued Presidential Instruction Republic of Indonesia Number 17 of 2011 about Prevention and Combating of Corruption Action 2012. This instruction contains the enactment of whistleblowing system.

Institution that became a pioneer in the implementation of the whistleblowing system is the Directorate General of Taxation (Direktorat Jendral Pajak or DJP). In Presidential Instruction Republic of Indonesia Number 17 of 2011 , DJP is an institution that is prioritized in the implementation of the whistleblowing system. The existence of the whistleblowing system in DJP is expected to be to prevent and combat to any abuses. One of the aims whistleblowing systems in DJP is to rebuild public trust towards the DJP. DJP invites all employees to change the permissive culture into a culture corrective means it will never tolerate the violation. The entire tax officials and the public are expected to contribute actively to become a whistle-blower in the field of taxation.

Prevention efforts with the whistleblowing system have been applied to the DJP, officially, adopted since 2012. During 2012, the DJP recorded of 201 complains from whistle-blowers. This number increased by $63.4 \%$ compared to the prior issuance of Regulation of DJP Number: PER-22/PJ/2011. During the year 2013, the number of complains from whistle-blowers was 258, while in 2014, DJP recorded of 228 complaints from whistle-blowers [27]. It seems that the number of complaints from whistle-blowers significantly increased in beginning years of implementation of the system. However, it gradually decreases in 2014. In addition, there was also an employee who abuses their authority. It makes the effectivity of whistleblowing as means of prevention of corruption is questionable.

Based on the extant literature, the intention to report the violations are influenced by several factors such as invidual factors, and organizational factors. Most prior studies, particularly in outside Indonesia, have examined these factors. Meanwhile, Indonesia, particularly Javanese, has unique culture, namely ewuh pakewuh. This culture has not been widely examined in the context of whistleblowing intention.

\footnotetext{
* Corresponding author: Widagdo2002@yahoo.com
} 
Whistleblowing reporting channels in DJP are included in the internal whistleblowing system. Thus, the internal whistleblowing intention deemed appropriate in the context of this study. The reasons to investigate whistleblowing intentions rather than actions whistleblowing are because of the impossibility and difficulty carrying out investigations of unethical behavior in the workplace by observation [14].

Based on the background of the problems described above, the formulation of the issues to be addressed in this study is as follows. How do ewuh-pakewuh culture, attitude toward whistleblowing, perceived behavioral control, personal responsibility for reporting, personal cost of reporting affect on whistleblowing intention of DJP`s civil servants? How does the perceived organizational moderate relationships between attitude toward whistleblowing, perceived behavioral control, personal responsibility of reporting, and personal cost of reporting and whistleblowing intention of DJP's civil servants?

\section{Literature Review and Hypotheses Development}

\subsection{Whistleblowing}

A 1985 study [26] define whistleblowing as the disclosures made by members or former members of the organization of an illegal, immoral, or otherwise violate the legal legitimacy under the control of their leaders to individuals or organizations that can effect remedial action. Reporting violations (whistleblowing) is disclosure violations or disclosure of acts that are unlawful, unethical or other actions that may be detrimental to the organization and its stakeholders, carried out by a member or leader of the organization to the leadership of other authorized institution follow up action on the breach [22]. Whistleblowing intention referrs to the possibility of respondents report a violation that occurred [1].

Based on Regulation of DJP Number PER-22/PJ/2011, whistleblowing system in the DJP is a system that breach prevention and management reporting violations in the DJP. Whistleblowing system in DJP embraces three principles, namely the principle of prevention, early detection and proper investigation. DJP provides a whistleblowing system as a means for complaints either directly or indirectly. Complaints can be reported directly by way of the reporting coming directly to the Help Desk Directorate for Internal Transformation Decency Apparatus Resources (KITSDA). In addition, complaints also could indirectly report through call center, email, website and writing a confidential letter to head of Unit DJP.

\subsection{Short Literatur Review}

Various studies have been done on the outside and within Indonesia associated with the factors that influence the intention of whistleblowing [ie. 3, 6, 17, 18, 30]. These factors include cultural factors, demographics, personal cost, responsibility, organizational commitment, locus of control, and the seriousness of the offense.

A 2007 study [16] mentions five factors that influence the actions of whistleblowing: the psychological factor, cultural and ethical factors, structural factors, retaliation, and the type of wrongdoing. These factors will determine how individual actions when he finds violations. When people find their potential infringement damages, then the individual will consider various factors before making reporting. A 2002 study [6] examines the whistleblowing intentions on MBA students in China. The results indicate that locus of control moderates the relationship between votes and whistleblowing intentions judgment. In the study, respondents with an external locus of control are not possible to do whistleblowing. The respondents with an external locus of control will be deemed to uncover the secrets of ethical, but respondents who have an internal locus of control are more likely to report the error in question. A 2008 study [17] proves Confucian culture has a strong influence on whistleblowing intentions on professional accountants. The majority of respondents believe that the moral is the most important factor to encourage whistleblowing. In addition, the research also finds that the culture of guanxi and the fear of retaliation would be discouraged to take action whistleblowing.

A 2010 study [3] proves that attitude, perceived behavioral control, independence commitment, personal responsibility, and personal cost of reporting affect on the whistleblowing intentions public accountant in Barbados. Accountants, who have a positive attitude and high responsibility towards whistleblowing, will tend to do the reporting if he finds violations. The study proves that the organization support will increase the intention to do whistleblowing. Accountants will consider the difficulties in the process of reporting and the threat that would be obtained if the report violations. A 2013 study [18] compares the cultural factors that influence the tendency to report violations in China, Taiwan, and the US. The US has a greater disposition to engage in whistleblowing compared to China and Taiwan. In Taiwan and China, the intention to blow the whistle is affected by large amount of losses and influenced also by the impact of the practice is illegal, immoral or illegal on the company rather than that in the United States. This study reveals guanxi, or personal connections (network) has a great effect on the tendency for students whistleblowing Taiwan and China compared with American students. In another study, using a culture as variable, a study by [30] states that ethnic group influence on employee whistleblowing intentions. The study finds that the intention of doing whistleblowing employees come from the Javanese higher than employees come from non-Java region. 
Based on the above previous studies, the intention to report the violations are influenced by several factors. Therefore, this study will examine influence attitudes, perceived behavioral control, personal responsibility and personal cost of reporting on the intention of internal whistleblowing intention of employees in DJP. In addition, this study will examine also the moderating role of perceived organizational support. This research is important because, until now, there has been a few of empirical research in Indonesia, which examines the effect of ewuh-pakewuh culture on whistleblowing.

\subsection{Hypotheses Development}

\subsubsection{Ewuh-Pakewuh Culture and Whistleblowing}

Ewuh-Pakewuh culture is a Javanese culture. According [35], ewuh-pakewuh is a manifestation of the fundamental rules of Javanese life. In addition, according [13], ewuh-pakewuh culture is an attitude and behavior that contains cheekily and worry if the behavior or words will make other people hurt.

According to [19], one of the cultural factors in Indonesia is very influential on the public sector bureaucracy in Indonesia is the Javanese cultural patronage that induces excessive ewuh-pakewuh. It can be seen from the bureaucracy in Indonesia, where the eastern culture in the context of Javanese politeness ewuh pakewuh that is reluctant attitude or awe and uphold respect for the boss or a senior [31].

A 2008 study [17] investigates the influence of Confucian culture on whistleblowing in Taiwan. The result shows that the Confucian culture influences the intention to do whistleblowing of auditing practitioners. In addition, in recent study [18], they find that cultural factors influence the tendency of individuals to take action whistleblowing in the US, China, and Taiwan. In Indonesia, the influence of cultural factors on whistleblowing intention has been studied by [30]. The results show that Indonesian Financial Transaction Reports and Analysis Centre employees who come fom the Javanese have higher internal whistleblowing intention than the intention of employees come from non-Java region. Characters employees come from the Javanese, who tend to have attitudes of pakewuh and not outspoken, tend to avoid conflict. As a result, these Javanese employees do not want to engage in whistleblowing. Ewuh-pakewuh culture will discourage intention of employees to report violations. Based on the above, the proposed hypothesis is:

H1: Culture ewuh-pakewuh has a negative effect on the intention to do whistleblowing.

\subsubsection{Attitude toward Whistleblowing and Whistleblowing}

Theory of planned behavior (TPB) explains that the intention of the individual to perform a behavior is an indication of the tendency of individuals to perform a behavior and the direct antecedent of the behavior [2]. Intention to perform a behavior can be measured through three main determinants that affect the intention, namely attitude toward the behavior, subjective norm, and perceived behavioral control. Attitude towards behavior is a stage where people evaluate the advantages (favorable) and losses (unfavorable) on an action. Attitude is the individual votes on approval or disapproval of certain behaviors.

Individuals can have confidence that whistleblowing would be beneficial for the organization if it can be uncovered and losses can be prevented. Conversely, individuals also can have confidence in whistleblowing would prejudice the organization, for example, damaging the reputation of the organization. Then, the individual will evaluate the positive or negative side that will be experienced alone, for example, gain reward from the organization on whistleblowing action or the threat of the party reported. Their consideration process is referred to as the process of "attitude factor" experienced by the individual. The tendency of being supportive whistleblowing act logically would increase the interest to take whistleblowing action [34].

A 2009 study [28] finds that attitude has a significant effect on the intention whistleblowing on South Korean police. Othe prior studies [i.e.37, 4] prove that attitudes towards whistleblowing significantly affect the interest of civil servants to take action whistleblowing. Attitude will directly affect whistle=blowing intention, to assess how favorable or unfavorable an individual if he do whistleblowing [3]. Based on the above, the proposed hypothesis is:

H2: Attitude toward whistleblowing has a positive effect on the intention to do whistleblowing.

\subsubsection{Perceived Behavioral Control and Whistleblowing}

According [5], perceived behavioral control as an individual's belief in a degree of ease or difficulty required to perform certain actions. According to [29], perceived behavioral control refers to the individual's perception of the ease or difficulty in performing a behavior. According to TPB, the individual will perform an action if he is sure to measure the level of difficulty may be obtained. Intention to perform a behavior can be measured through a perceived behavioral control. Perceived behavioral control depends on the presence or absence of opportunities and barriers to behavior. 
A 2010 study [32] argues, if people can control themselves in the act that is based on perception, the higher the intention to become a whistle-blower. Perceived behavioral control is influenced by a combination of individual beliefs regarding the factors supporting or inhibiting to perform a behavior by the strength of feeling people will any factors supporting or inhibiting them. DJP has written rules and reporting channel that will support and facilitate the whistle-blower to report violations. Employees will have the intention to commit acts of whistleblowing when they have the perception that such action is easy to do, it is because there are mechanisms that support these actions. Based on the above, the proposed hypothesis is:

H3: Perceived behavioral control has a positive effect on the intention to do whistleblowing.

\subsubsection{Personal Responsibility for Reporting and Whistleblowing}

A 2010 study [21] identifies personal responsibility for reporting as one of the important variables that drive an individual's decision to report the violation information. According [20], personal responsibility is describes as a commitment to personal responsibility and moral obligation to report an unethical act. According [8], responsibility of reporting fraud actions can be influenced by a sense of social responsibility to co-workers and bosses, attitudes toward the profession, and the values of personal ethics. Individuals may feel obliged to report questionable actions by their moral (moral obligation or social responsibility), or a sense of commitment and loyalty to the organization (responsibility roles).

According [15], a decision to take action of whistleblowing depends on the perception of moral responsibility to report violations that occur within the organization. A 2010 study [3] proves that personal responsibility affects interest to do whistleblowing on internal auditor in Barbados. Prior studies [3] show that personal responsibility for reporting has a positive effect on the interest of the intention to commit acts of whistleblowing. Based on the above explanation, the proposed hypothesis is:

H4: Personal responsibility for reporting has as positive effect on the intention to do whistleblowing.

\subsubsection{Personal Cost of Reporting and Whistleblowing}

Personal cost of reporting is an individual assessment of the level of discomfort in reporting an unethical act [3]. This discomfort can be pressure, reprisals or retaliation from the offenders. According to [1], members of the institution have a contribution to prevent, deter and detect violations. However, in investigating the behavior of ethical decision makes whistleblowing against disclosure violation gets a lot of obstacles in the reporting process. A 2005 study [23] shows that the threat of retaliation is negatively correlated with interest to do whistleblowing. Thus, the risks to be faced by whistleblowers must be taken into consideration before doing the reporting.

Individuals with the ability to influence others, a strong position, and authority to replace an employee in the organization tends to have the perception that the personal cost of reporting that will result from the behavior of whistleblowing will be relatively low, so that the individual had the intent higher to take action whistleblowing. Intention employees to report violations to be stronger when the personal cost of reporting is lower rated or personal responsibility to report violations rated is higher [30]. Intention employees to report violations is more powerful when the personal cost reporting is perceived lower or personal responsibility to report violations is perceived higher. Based on the above explanation, the proposed hypothesis is:

H5: Personal cost of reporting for reporting has a negative effect on the intention to do whistleblowing.

\subsubsection{Perceived Organizational Support}

Perceived organizational support is one form of normative isomorphism. Normative isomorphism aims to increase the professionalism of employees by assigning the most appropriate structure, and perceived organizational support is seen as one of the design of normative isomorphism [9]. According to [3], perceived organizational support is the extent to which an individual perceives that the organization values and supports the actions of individuals. Perceived organizational support encourages employees to adapt to organizational goals.

Based on social exchange theory, employees are more likely to feel obligated to commit to the organization if they get a high degree of organizational support [10]. Thus, employees will feel safe making decisions such as reporting unethical when perceived organizational supports these actions. According [11], a positive relationship, which valued employee perceptions and gain awareness by the organization with awareness in carrying out job responsibilities, affective involvement, and encouraged to innovate.

A 2010 study [3] shows that moderate the relationship of perceived organizational support will increase whistleblowing actions. According [36], protection system moderates the relationship public service motivation and internal whistleblowing intentions. Based on the above explanation, the proposed hypotheses are:

H6a: Perceived organizational support will moderate relationship between attitude toward whistleblowing and intention to do whistleblowing. 
H6b: Perceived organizational support will moderate relationship between perceived behavioral control and intention to do whistleblowing.

H6c: Perceived organizational support will moderate relationship between personal responsibility for reporting and intention to do whistleblowing.

H6d: Perceived organizational support will moderate relationship between personal cost of reporting and intention to do whistleblowing.

\section{Research Method}

This research is a quantitative research by using primary data. The population in this study is employees of Regional Office DJP in Central Java I and II. The sampling technique is census that population is used as a sample. The data collection methode in the study is questionnaires that are adopted from some prior studies. The ewuh pakewuh quetionnaire is adopted from a 2011 study [31]. For variable attitude toward whistleblowing and perceived behavioral control, the questionnaire is adopted from a 2010 study [3]. The questionnaire of personal responsibility for reporting and the personal cost of reporting adopt the questionnaire of 2013 studies [30, 37]. The questionnaire of perceived organizational support is developed based on 2010 study [3].

This study used the intention simulation, which uses vignette. The respondents were asked to evaluate and to make choices based on the information provided. Thevignette used hypothetical cases of occupational fraud in accordance with Regulation of DJP Number: PER-22/PJ/2011, which was developed by the researchers based on the level of seriousness. The first vignette was a vignette to represent the serious corruption, which relates acceptance of bribes. The second vignette was a vignette to represent the less serious corruption, which relates to a mark-up in a procurement project. The validity of the contents of the scenario previously consulted with tax officials, who had the expertise and capability in handling cases of whistleblowing.

Analysis of the data in this study uses the approach of Partial Least Squares (PLS). PLS is one of the statistical methods of Structural Equation Modeling (SEM) based variants. The theoretical framework is presented briefly in the image below:

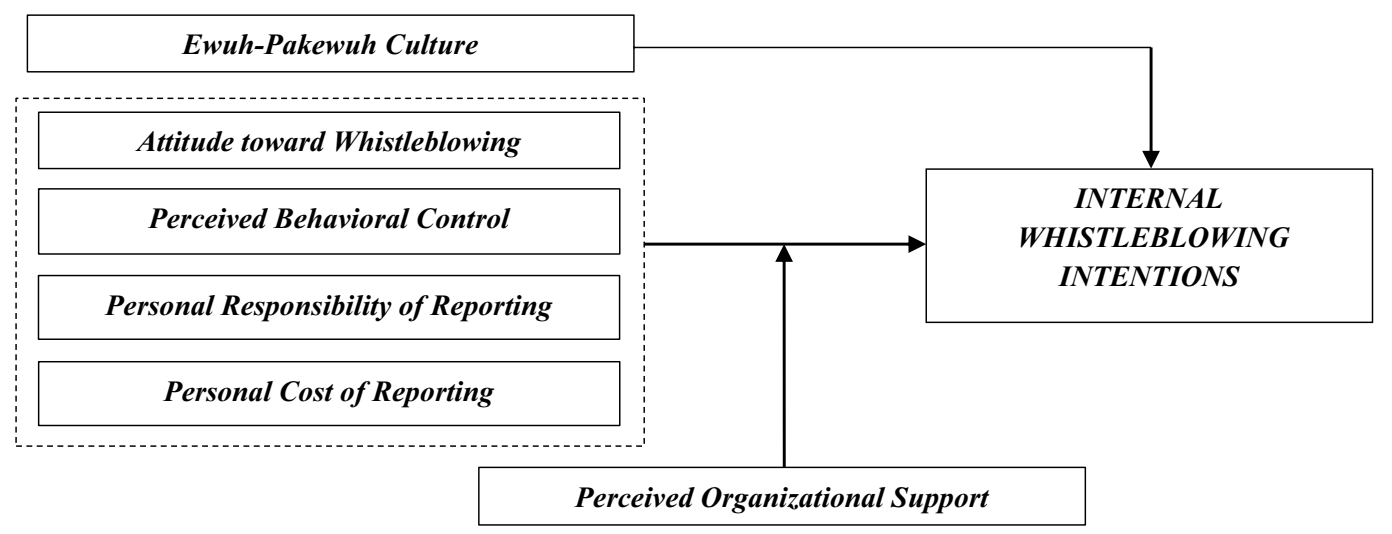

Fig. 1. Theoretical Framework

\section{Results and Discussion}

\subsection{Results}

The data in this study is a primary data obtained using questionnaires distributed to tax officials at the Regional Office of Directorate General of Taxation, Central Java Central Java I and II. The number of distributed questionnaires were 255 copies, 135 copies were distributed at the Regional Office of Directorate General of Taxes Central Java I and 120 copies 
were distributed at the Regional Office of Directorate General of Tax of Central Java II. The survey was conducted in one month, from December 16th, 2015 until January 18th, 2016.

The number of collected questionnaires is 128 copies and as many as of 11 copies is incomplete, so that only 117 copies can be used for this research. The respondents are mostly male (64.96 percent). The respondents hold undergraduate degrees are 70 respondents (59.83 percent). Most respondents are in the age range of 25-35 years (50.43) percent. The respondents mostly occupy executive positions with a number of 99 respondents (84.6 percent) and the percentage of respondents who had experience working in the DJP for $>11$ years is 50.43 percent.

\subsubsection{Case 1: Serious Corruption}

This model has a value of goodness of fit of 0.596915 , so the value of goodness of fit is categorised as large. Based on the result of the calculation of goodness of fit, it can be concluded that the modification of the model at this stage has met the criteria or fit. . This $\mathrm{R}$ square of the model is 54.19 percent.

For a hypothetical two-tailed with alpha testing of 5 percent, the value of the path coefficient indicates an accepted hypothesis if the value of t-statistic is greater than 1.96. Table 1shows that ewuh-pakewuh culture (EP) has t-statistic value of 2.923345. This indicates that the result is significant because the t-statistic value is greater than 1.96. Based on the results SmartPLS, it can be concluded that H1 is empirically proved (H1 accepted). Attitude toward whistleblowing (ATT) has the value of t-statistic of 15.260580 , so it can be concluded that the H2 is accepted. Perceived behavioral control (PBC) has a tstatistic value of 14.224069 , so the relationship is significant. However, unlike our expectation, the coefficient path is a negative, thus $\mathrm{H} 3$ is empirically rejected. Personal responsibility for reporting of (PR) has a t-statistic value of 0.820351 , so $\mathrm{H} 4$ is rejected. Personal cost of reporting (PC) has a t-statistic value of 0.751600 , so that it can be concluded H5 is rejected. In terms of interaction variable, the interaction between perceived organizational support with perceived behavioral control and its interaction with personal cost have a t-statistic value more than 1.96. This indicates that the H6b and H6c are empirically proved. In contrast, H6a and H6d are empirically rejected.

Table 1. Serious Corruption Case

\begin{tabular}{|l|c|c|c|c|c|}
\hline & $\begin{array}{c}\text { Original } \\
\text { Sample (O) }\end{array}$ & $\begin{array}{c}\text { Sample } \\
\text { Mean (M) }\end{array}$ & $\begin{array}{c}\text { Standard } \\
\text { Deviation } \\
(\text { STDEV) }\end{array}$ & $\begin{array}{c}\text { Standard } \\
\text { Error } \\
(\text { STERR) }\end{array}$ & $\begin{array}{c}\text { T Statistics } \\
(\mid \text { O/STERR|) }\end{array}$ \\
\hline EP -> WBI & -0.066487 & -0.070211 & 0.022744 & 0.022744 & 2.923345 \\
\hline ATT -> WBI & 0.513034 & 0.505496 & 0.033618 & 0.033618 & 15.260580 \\
\hline PBC -> WBI & -0.341217 & -0.344445 & 0.023989 & 0.023989 & 14.224069 \\
\hline PR -> WBI & 0.027178 & 0.038011 & 0.033130 & 0.033130 & 0.820351 \\
\hline PC -> WBI & 0.018276 & 0.024244 & 0.024316 & 0.024316 & 0.751600 \\
\hline ATT * POS -> WBI & -0.047894 & -0.049356 & 0.050415 & 0.050415 & 0.949994 \\
\hline PBC * POS -> WBI & 0.143576 & 0.130231 & 0.039295 & 0.039295 & 3.653767 \\
\hline PR * POS -> WBI & 0.196985 & 0.203299 & 0.052767 & 0.052767 & 3.733132 \\
\hline PC * POS -> WBI & -0.091845 & -0.033971 & 0.080740 & 0.080740 & 1.137539 \\
\hline
\end{tabular}

\subsubsection{Case 2: Less Serious Corruption}

The value of goodness of fit of the model is 0.669780 , which is categorized large. Based on the calculation of goodness of fit, it can be concluded that the modification of the model at this stage mets the criteria or fit. This R square of the model is 46.76 percent.

Table 2 shows that ewuh-pakewuh culture (EP) has value of t-statistic of 0.750402 . This indicates that H1 is rejected. Attitude toward whistleblowing (ATT) has the value of t-statistic of 6.343492, so it can be concluded that the H2 is accepted. Like the prior result, perceived behavioral control (PBC) has a t-statistic value of 5.714985, but the coefficient path is a negative. Thus, H3 is rejected. The responsibility for reporting of personal (PR) has a t-statistic value of 13.200226, so H4 is accepted. The personal cost of reporting (PR) has t-statistic value of 3.909477, so that it can be concluded H5 is accepted. In terms of the interaction variables, there are no hypotheses that could be proved. 
Table 2. Less Serious Corruption Case

\begin{tabular}{|l|c|c|c|c|c|}
\hline & $\begin{array}{c}\text { Original } \\
\text { Sample (O) }\end{array}$ & $\begin{array}{c}\text { Sample Mean } \\
(\mathbf{M})\end{array}$ & $\begin{array}{c}\text { Standard } \\
\text { Deviation } \\
(\text { STDEV) }\end{array}$ & $\begin{array}{c}\text { Standard } \\
\text { Error } \\
\text { (STERR) }\end{array}$ & $\begin{array}{c}\text { T Statistics } \\
(\mid \mathbf{O} / \text { STERR } \mid)\end{array}$ \\
\hline EP -> WBI & 0.018221 & 0.025978 & 0.024282 & 0.024282 & 0.750402 \\
\hline ATT -> WBI & 0.177189 & 0.168756 & 0.027932 & 0.027932 & 6.343492 \\
\hline PBC -> WBI & -0.181232 & -0.174754 & 0.031712 & 0.031712 & 5.714985 \\
\hline PR -> WBI & 0.465643 & 0.451220 & 0.035275 & 0.035275 & 13.200226 \\
\hline PC -> WBI & -0.117125 & -0.124116 & 0.029959 & 0.029959 & 3.909477 \\
\hline ATT * POS -> WBI & -0.103019 & -0.062626 & 0.082852 & 0.082852 & 1.243407 \\
\hline PBC * POS -> WBI & -0.132441 & -0.122359 & 0.027802 & 0.027802 & 4.763703 \\
\hline PR * POS -> WBI & 0.044744 & 0.029279 & 0.085277 & 0.085277 & 0.524683 \\
\hline PC * POS -> WBI & 0.030089 & 0.007852 & 0.036724 & 0.036724 & 0.819344 \\
\hline
\end{tabular}

\subsection{Discussion}

The results of hypothesis testing show that $\mathrm{H} 1$ indicates mixed result. This hypothesis is accepted in serious case, whereas the hypothesis is rejected and not empirically proven in less serious corruption case. This means that effect of ewuhpakewuh culture on whistleblowing intention depends on the level of corruption case. In terms of serious corruption case, the employees tend to avoid action that will make hurt other employee, who particularly has managerial position. Rotation system and moving staff regularly might be capable of reducing a sense ewuh-pakewuh in DJP. Staffing system in the DJP in a position is determined by a maximum period of three years. After three years, he will do rotational placement. The rotation of employees is also intended to prevent violations. According [24], organizations/government agencies might face cultural transition, although, some characteristics paternalistic culture in everyday life can still be found.

The results indicate that the hypothesis H2 is accepted on both cases. Attitudes towards whistleblowing affect the intention to commit acts of whistleblowing. Individuals can have a confidence that whistleblowing would have a positive and a negative sides. Then, people would consider a positive or a negative side of his actions. The consideration process is referred to as the process of "attitude" experienced by these employees. The results are consistent with the theory of planned behavior that perceived behavioral control is an aspect that affects an individual's decision to perform an action. The result of this study confirms the results of previous research [28, 3, 32, 37, 4]. Individuals will assess whether the act of whistleblowing will be favorable or unfavorable if he/she does whistleblowing.

Unlike the expectation, the hypothesis H3 is rejected on both cases because the coefficient is a negative. It means that the greater of the perceived behavioral control causes the weaker of the intention to perform the whistleblowing. It is contrary with the theory of planned behavior that if an employee can control themselves in accordance with the perception that is believed to act whistleblowing, it will cause the intention on the employee to take action whistleblowing. The consequence of doing whistleblowing might deter the intention of the employee.

The hipotesis H4 is empirically proved and supported on less serious corruption case, but not in serious corruption. It means that the employee have higher personal responsibility for reporting violation in less serious case than that in serious case. The employees might view that reporting serious case has a negative consequence and they prefer not to do whistleblowing. The results of this study are consistent with prior studies $[3,21]$ that personal responsibility for reporting a positive effect on the interest of the intention to commit acts of whistleblowing.

Personal cost of reporting empirically has a negative effect on employee intention to commit acts of whistleblowing on less serious corruption case. It seems that the employees feel that reporting of less serious corruption has low personal reporting cost, so it does not have the impact that would harm themself. The result is consistent with previous studies $[7,3,30,37,12,4]$ that the personal cost of reporting negatively affect intention to commit acts of whistleblowing.

The results show that perceived organizational support moderates the relation between perceived behavioral control with whistleblowing intentions in both cases. It means that organizational supports might provide a safety and mitigate a negative consequence of doing whistleblowing. Perceived organizational support moderates relation of personal responsibility with the whistleblowing intentions in serious corruption case. This means perceived organizational support will increase whistleblowing intentions. Whistleblowing policies provide an ease in reporting and are able to increase the personal responsibility to report violations.

The interaction perceived organizational support with personal cost of resporting and personal repondsibility of reporting do not significantly affect whistleblowing intentions in less serious case and serious case as well. This may occur because employees feel the support of the organization in action whistleblowing, only felt able to provide ease in conveying 
violation information. Whistleblowing system in DJP allows the employee to provide information of the violation; however, this support for the whistleblowing does not make employees have a positive attitude towards whistleblowing. Regulation of whistle-blower protection for both the central government and the DJP itself is not able to improve safety of employees to report violations.

\section{Conclusion}

Whistleblowing is an action taken by members of the organization to uncover violations that occur in organizations. DJP has implemented a whistleblowing system that is internal whistleblowing channels. Whistleblowing system is a system of prevention and identification of fraud/breach that would occur in an organization. With the whistleblowing system, employees will avoid any violation and are expected to participate actively in the participation of preventing violations. Nevertheless, there are still cases were uncovered after implementation of whistleblowing in DJP. This indicates the whistleblowing system functions as a prevention system has not been able to run well.

The results show that effect of the culture ewuh-pakewuh, personal respondsibility of reporting, and personal costs of reporting on the whistleblowing intention provide mixed findings. It seems that the level violation (i.e. level of corruption) affect the result. Similarly, the result of interaction variables are also mixed and it seems depend of type of violation.

This study has several limitations. First, the respondents in this study is only DJP's civil servants in the Central Java Region I and II, so that research results can not be generalized. Second, this study uses a questionnaire to collect data that the bias is likely to occur. Suggestions for further research can add a more comprehensive method. For example, future study might employ amixed methods by interviewing the informan to clarify the results from quantitative approach. Subsequent research could also examine other factors, such as the effect of educational level as well as rotation and mutation.

\section{References}

1. S.A. Ahmad, R.M. Yunos, R.A.R. Ahmad, Z.M. Sanusi. Procedia, 164, 445-450 (2014)

2. I. Ajzen. OBHDP, 50(2), 179-211 (1991)

3. P.A. Alleyne. Doctoral Diss. Univ. of Bradford, UK (2010)

4. R. Bagustianto, Nurkholis. SNA XVIII Medan. USU (2015)

5. A. Bandura. New Jersey: Prentice Hall (1997)

6. R.K. Chiu. MAJ, 17(9), 581-588 (2002)

7. L.M. Cortina, Magley, J. Vicki. JOHP, 8(4), 247-265 (2003)

8. M. Curtis. JBE 68(2), 191-209 (2006)

9. P.J. DiMaggio, W.W. Powell. ASM, 17, 143-166 (1983)

10. R. Eisenberger, R. Huntington, S. Hutchison, D. Sowa. JAP, 71, 500-507 (1986)

11. R. Eisenberger, P. Fasolo, V. Davis-LaMastro. JAP, 75(1), 51-59 (1990)

12. C.K. Eller. Thesis. VCU, US (2014)

13. A. Frinaldi, M.A. Embi. Humanus 13(1), 68-75 (2014)

14. N.A. Ghani, J. Galbreath, R. Evans. $A G M S$, 3(1), 1-18 (2011)

15. J.W. Graham, J. W. ROB, 8,1-52 (1986)

16. H. Hassink, M. de Vries, L. Bollen. JBE, 75(1), 25-44 (2007)

17. D. Hwang, B. Staley, Y.T. Chen, J.S. Lan. MAJ, 23(5), 504-526 (2008)

18. D. Hwang, B. Staley, Y. Tsai, C.L. Chu. IJAFR, 3(2), 202-224 (2013)

19. Ihsan, F. Ref. Budaya Kerja Birokrasi (2014)

20. S.E. Kaplan, S.M. Whitecotton. $A A A$, 20(1), 45-64 (2001)

21. M. Keil, A. Tiwana, R. Sainsbury, Sneha. Persp. Dec. Sciences, 41(4), 787-812 (2010)

22. KNKG (2008)

23. M.J.R. Magnus, C. Viswesvaran. JBE, 62(3), 277-297 (2005)

24. A. Maskun. JAM, 7(1), 162-172 (2008)

25. E.S. Muslim, E. S. Thesis. ITB, Indonesia (2000)

26. J.P. Near, M.P. Miceli. JBE, 4(1), 1-16 (1985)

27. DJP Annual Report 2014 (2014)

28. H. Park, J. Blenkinsopp. JBE, 85(4), 545-556 (2009)

29. C.H. Ponnu, K. Naidu, W. Zamri. IRBRP, 4(1), 276-298 (2008)

30. W. Septianti, W. SNA XVI Manado. UNSRAT: 1063-1094. (2013)

31. H.I. Soeharjono. Doctoral Dis. UGM, Indonesia (2011)

32. A. Sulistomo. Working Papers. UNDIP, Indonesia (2012)

33. E. Suryono. Thesis. UNDIP, Indonesia (2014) 
34. D.H. Tobing.. Thesis. UGM, Indonesia (2010)

35. W. Vandenabeele, A.M. Kjeldsen. EGPA conference 2011, Romania (2011)

36. R.D. Winardi. JIEB, 28(3), 361. (2013) 